\title{
Supporting Information for \\ Indoor illumination of terpenes and bleach emissions leads to particle formation and growth
}

Chen Wang, ${ }^{1 *}$ Douglas B. Collins, ${ }^{1,2}$ Jonathan P.D. Abbatt ${ }^{1}$

1 Department of Chemistry, University of Toronto, Toronto, ON, Canada, M5S 3H6

2 Department of Chemistry, Bucknell University, Lewisburg, PA, USA, 17837

*To whom correspondence should be addressed: irenechen.wang@mail.utoronto.ca

Table of Content:

Table S1-S2

Figure S1-S9

Text S1-S5 
Table S1. Experiment summary

\begin{tabular}{|c|c|c|c|c|c|c|c|c|c|c|}
\hline \multirow[t]{2}{*}{$\#$} & \multirow{2}{*}{\multicolumn{2}{|c|}{$\begin{array}{l}\text { Initial limonene } \\
\text { or } \\
\alpha \text {-pinene (ppb) }\end{array}$}} & \multicolumn{2}{|c|}{$\begin{array}{l}\text { Source } \\
\text { (ppm) }\end{array}$} & \multicolumn{2}{|c|}{$\begin{array}{c}\text { Chamber } \\
\text { (ppb) }\end{array}$} & \multirow{2}{*}{$\begin{array}{c}\text { Decay time } \\
\text { constant in } \\
\text { dark }(s)^{d}\end{array}$} & \multirow{2}{*}{$\begin{array}{l}\text { Number of } \\
\text { replicates }\end{array}$} & \multirow{2}{*}{$\begin{array}{c}\text { Particle } \\
\text { concentration } \\
\left(\mu \mathrm{g} / \mathrm{m}^{3}\right)\end{array}$} & \multirow[t]{2}{*}{$\begin{array}{c}\text { SOA } \\
\text { yieldg }\end{array}$} \\
\hline & & & $\mathrm{HOCl}$ & $\mathrm{Cl}_{2}$ & $\mathrm{HOCl}$ & $\mathrm{Cl}_{2}$ & & & & \\
\hline \multirow[t]{2}{*}{ 1a) } & \multirow{2}{*}{ limonene } & \multirow{2}{*}{1000} & \multirow[t]{2}{*}{200} & \multirow[t]{2}{*}{270} & \multirow[t]{2}{*}{2000} & \multirow[t]{2}{*}{2700} & \multirow{2}{*}{$\begin{array}{l}60 \pm 28 \text { (40- } \\
100) \text { (dark) }\end{array}$} & 2 & $665-2580$ & $12-47 \%$ \\
\hline & & & & & & & & $2^{f}$ & $1345-1550$ & $24-28 \%$ \\
\hline 1b) & limonene & 1000 & 200 & 270 & 2000 & 2700 & $40{\text { (light })^{a}}^{a}$ & 1 & 2535 & $46 \%$ \\
\hline 2) & limonene & 200 & 20 & 27 & 700 & 950 & $\begin{array}{c}1200 \pm 780 \\
(600-2000)\end{array}$ & 6 & $327-905$ & $30-82 \%$ \\
\hline 3) & limonene & 200 & 2 & 2.7 & 60 & 80 & 2500 & 1 & 313 & $28 \%$ \\
\hline 4) & limonene & 20 & 2 & 2.7 & 200 & 270 & N.A. & 3 & $39-45$ & $35-41 \%$ \\
\hline 5) & $\alpha$-pinene & 1000 & 200 & 270 & 2000 & 2700 & 1500 & 1 & 310 & $6 \%$ \\
\hline 6) & limonene & 1000 & - & - & 0 & $4000^{b}$ & 650 & 1 & 1923 & $35 \%$ \\
\hline 7a) & control & 0 & 200 & 270 & 2000 & 2700 & N.A. & 1 & $19^{c}$ & N.A. \\
\hline 7b) & control & 0 & 2 & 2.7 & 200 & 270 & N.A. & 1 & 3.9 & N.A. \\
\hline 7c) & control & 0 & 2 & 2.7 & 80 & 100 & N.A. & 1 & 4 & N.A. \\
\hline
\end{tabular}

${ }^{a}$ Turn on indoor fluorescent lights before adding $\mathrm{HOCl}$ and $\mathrm{Cl}_{2}$ in to the chamber.

${ }^{b}$ Control experiment with only $\mathrm{Cl}_{2}$ added to the chamber as described in Text $\mathrm{S} 1$.

c Particle formation was observed during control experiments, but with significantly lower concentrations compared to experiments with limonene added in the chamber. This is likely due to residual VOCs in the chamber.

${ }^{d}$ e-folding time for limonene (i.e., the time to decrease to $1 /$ e of the initial limonene concentration)

e The maximum particle mass concentration during each experiment $\left(\mu \mathrm{g} / \mathrm{m}^{3}\right)$

${ }^{f}$ Particles were collected on filters during these two experiments for off-line ESI-MS analysis.

${ }^{\mathrm{g}}$ Estimated SOA yield assuming all limonene or $\alpha$-pinene has reacted away and contributes to SOA formation. The mass of SOA used for the yield calculation is the maximum particle mass measured with SMPS. Particle loss to chamber walls is not corrected. Particle density is assumed to be $1.4 \mathrm{~g} / \mathrm{cm}^{3}$. 
Table S2. Calculated photolysis rate, photolysis lifetime, $\mathrm{OH}$ and $\mathrm{Cl}$ production rate of $\mathrm{HOCl}$ and $\mathrm{Cl}_{2}$ under indoor fluorescent lights or window sunlight using photon flux measurement plotted in Figure S2.

\begin{tabular}{|c|c|c|c|c|}
\hline & \multicolumn{2}{|c|}{ indoor fluorescent lights } & \multicolumn{2}{|c|}{ window sunlight ${ }^{a}$} \\
\hline & $\begin{array}{c}\mathrm{HOCl} \\
(200-420 \mathrm{~nm})\end{array}$ & $\begin{array}{c}\mathrm{Cl}_{2} \\
(260-550 \mathrm{~nm})\end{array}$ & $\begin{array}{c}\mathrm{HOCl} \\
(200-420 \mathrm{~nm})\end{array}$ & $\begin{array}{c}\mathrm{Cl}_{2} \\
(260-550 \mathrm{~nm})\end{array}$ \\
\hline Photolysis rate constant, $J\left(\mathrm{~s}^{-1}\right)$ & $7.21 \times 10^{-7}$ & $5.24 \times 10^{-6}$ & $(3.76-10.7) \times 10^{-7}$ & $(8.71-23.5) \times 10^{-6}$ \\
\hline Lifetime (hr) & 385 & 53 & $260-740$ & $12-32$ \\
\hline $\mathrm{OH}$ production rate $\left(\text { molec } \mathrm{cm}^{-3} \mathrm{~s}^{-1}\right)^{\mathrm{b}}$ & $3.5 \times 10^{7}$ & N.A. & $(1.85-5.25) \times 10^{7}$ & N.A. \\
\hline $\mathrm{Cl}$ production rate $\left(\text { molec } \mathrm{cm}^{-3} \mathrm{~s}^{-1}\right)^{\mathrm{b}}$ & $3.5 \times 10^{7}$ & $3.6 \times 10^{8}$ & $(1.85-5.25) \times 10^{7}$ & $(5.78-15.6) \times 10^{8}$ \\
\hline
\end{tabular}

\footnotetext{
${ }^{a} \mathrm{~A}$ range of photolysis rate and $\mathrm{OH} / \mathrm{Cl}$ production rate is provided for the measured photon intensity at 6 different time points as plotted in Figure S2.

${ }^{\mathrm{b}} \mathrm{OH}$ and $\mathrm{Cl}$ production rate was calculated for mixing ratios of 2 and $2.7 \mathrm{ppm} \mathrm{HOCl}$ and $\mathrm{Cl}_{2}$.

Quantum yield of $\mathrm{Cl}$ (or $\mathrm{OH}$ ) is assumed to be 1 for photolysis of $\mathrm{HOCl}$ and 2 for $\mathrm{Cl}_{2}$.
} 
(a) Add limonene in the chamber

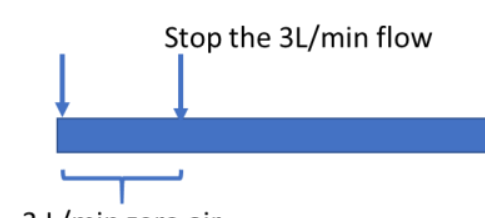

$3 \mathrm{~L} / \mathrm{min}$ zero air flow for $15 \mathrm{~min}$
Turn on fluorescent

lights or exposure

to sunlight

(b)

Add limonene

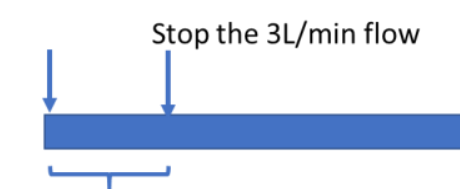

$3 \mathrm{~L} /$ min zero air flow added for $15 \mathrm{~min}$
Turn on fluorescent lights or exposure

to sunlight

Particle formation with lights on

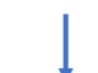




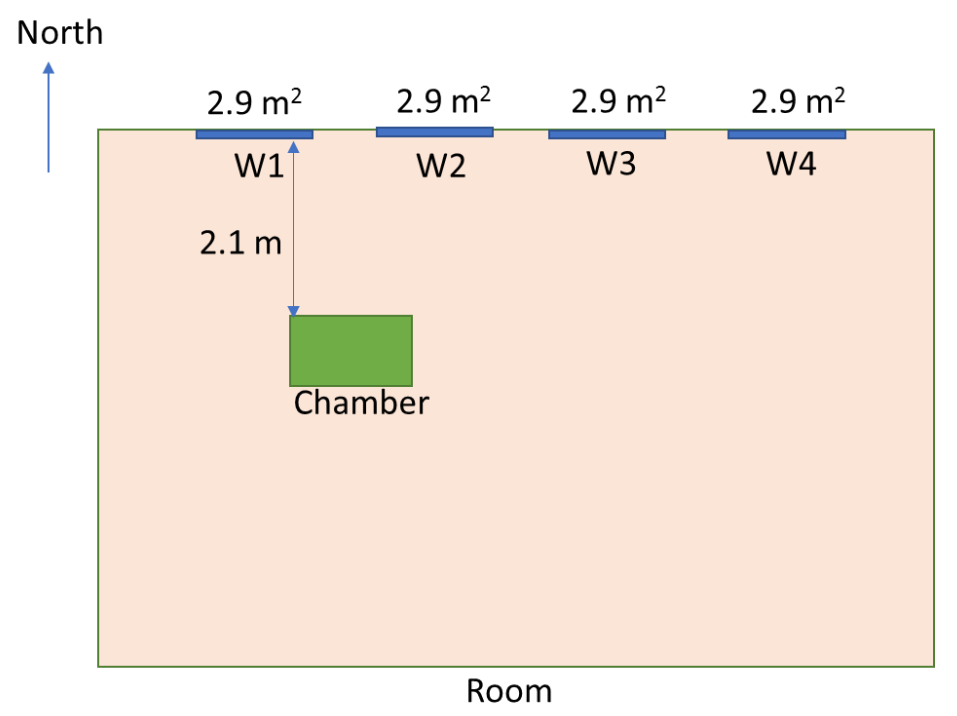

Figure S3. Location of the Teflon chamber and windows in the laboratory in Toronto. The sizes of the chamber, windows and the room in the figure are only for illustration purpose and are not to scale. Ceiling indoor fluorescent lights were kept on during the experiments. W1, W2, W3 and W4 are four windows, each with area of $2.9 \mathrm{~m}^{2}$. 


\section{Text S1. $\mathrm{Cl}_{2}$ only experiment}

$\mathrm{Cl}_{2}$ was added to the chamber using a glass bulb $(2 \mathrm{~L})$. The glass bulb was initially evacuated with an oil pump. Then $\mathrm{Cl}_{2}$ from a chlorine gas cylinder was added to the bulb to approximately 10 torr, measured by a capacitance manometer (Baratron, MKS Instruments). The bulb was subsequently filled with clean air to a total pressure of 1000 torr, leading to a $\mathrm{Cl}_{2}$ mixing ratio of $10^{4} \mathrm{ppm}$ in the bulb. By opening the valve connecting the bulb to the chamber, $\mathrm{Cl}_{2}$ flowed from the bulb (at 1000 torr) to the chamber (at atmospheric pressure, i.e. 760 torr) due to the pressure difference. The bulb was disconnected from the chamber (by closing the valve) when the pressure of the bulb decreased to 800 torr. The final mixing ratio of $\mathrm{Cl}_{2}$ in the $1 \mathrm{~m}^{3}$ chamber is approximately $4 \mathrm{ppm}$, which is close to the mixing ratio of $\mathrm{Cl}_{2}$ for other experiments with $\mathrm{HOCl}$ and $\mathrm{Cl}_{2}$ mixture. Limonene decayed away after adding $\mathrm{Cl}_{2}$ into the chamber in the dark, at a slower rate than for experiments with $\mathrm{HOCl}$ and $\mathrm{Cl}_{2}$, suggesting faster reaction of $\mathrm{HOCl}$ with limonene. After turning on indoor fluorescent lights, aerosol formation started due to reaction with $\mathrm{Cl}$ formed from photolysis of $\mathrm{Cl}_{2}$.

\section{Text S2. Details of the PTR-MS measurement}

The inlet flow of the PTR-MS was at $0.1 \mathrm{~L} / \mathrm{min}$. A piece of perfluoroalkoxy (PFA) tubing (o.d.: $0.635 \mathrm{~cm}$; length: $<1 \mathrm{~m}$ ) was used to connect the chamber air with the PTR-MS inlet for PTR-MS measurement. The PTR-MS uses protonated water as the reagent ion $\left(\mathrm{H}_{3} \mathrm{O}^{+}\right)$. The ions transmitted through the drift tube are then extracted into the quadrupole mass spectrometer operated under either the scan mode (for preliminary experiments) or selected ion mode (for most experiments). The water flow to the ion source was kept at $9.5 \mathrm{sccm}$. The drift tube voltage was kept at $546 \mathrm{~V}$ and the drift tube chamber temperature was $50^{\circ} \mathrm{C}$. The source current was set at $6.5 \mathrm{~mA}$. The pressures for the drift tube chamber and the detector chamber of the PTR-MS were 2.1-2.2 mbar and (9.2-9.5) $\times 10^{-6} \mathrm{mbar}$, respectively. The resulting E/ $\mathrm{N}$ ratio was 138-145 Townsend ( $\mathrm{Td}$ ) ( $\mathrm{N}$ corresponding to the number density of the gas in the drift tube, $\mathrm{E}$ is the electric field over the length $(8 \mathrm{~cm})$ of the drift tube; $\left.1 \mathrm{Td}=10^{-17} \mathrm{~V} \mathrm{~cm}^{2}\right)$. The intensities of the water cluster $\left(\mathrm{H}_{3} \mathrm{O}^{+} \cdot \mathrm{H}_{2} \mathrm{O}, \mathrm{m} / \mathrm{z} 37\right), \mathrm{NO}^{+}(\mathrm{m} / \mathrm{z} 30)$ and $\mathrm{O}_{2}{ }^{+}(\mathrm{m} / \mathrm{z} 32)$ relative to $\mathrm{m} / \mathrm{z} 21$ were $0.09-0.24 \%, 0.06-0.14 \%$ and $1.32-2.80 \%$, respectively. Data for different ions were normalized to the reagent ion signal at $\mathrm{m} / \mathrm{z} 21$ $\left(\mathrm{H}_{3}{ }^{18} \mathrm{O}^{+}\right)$. 


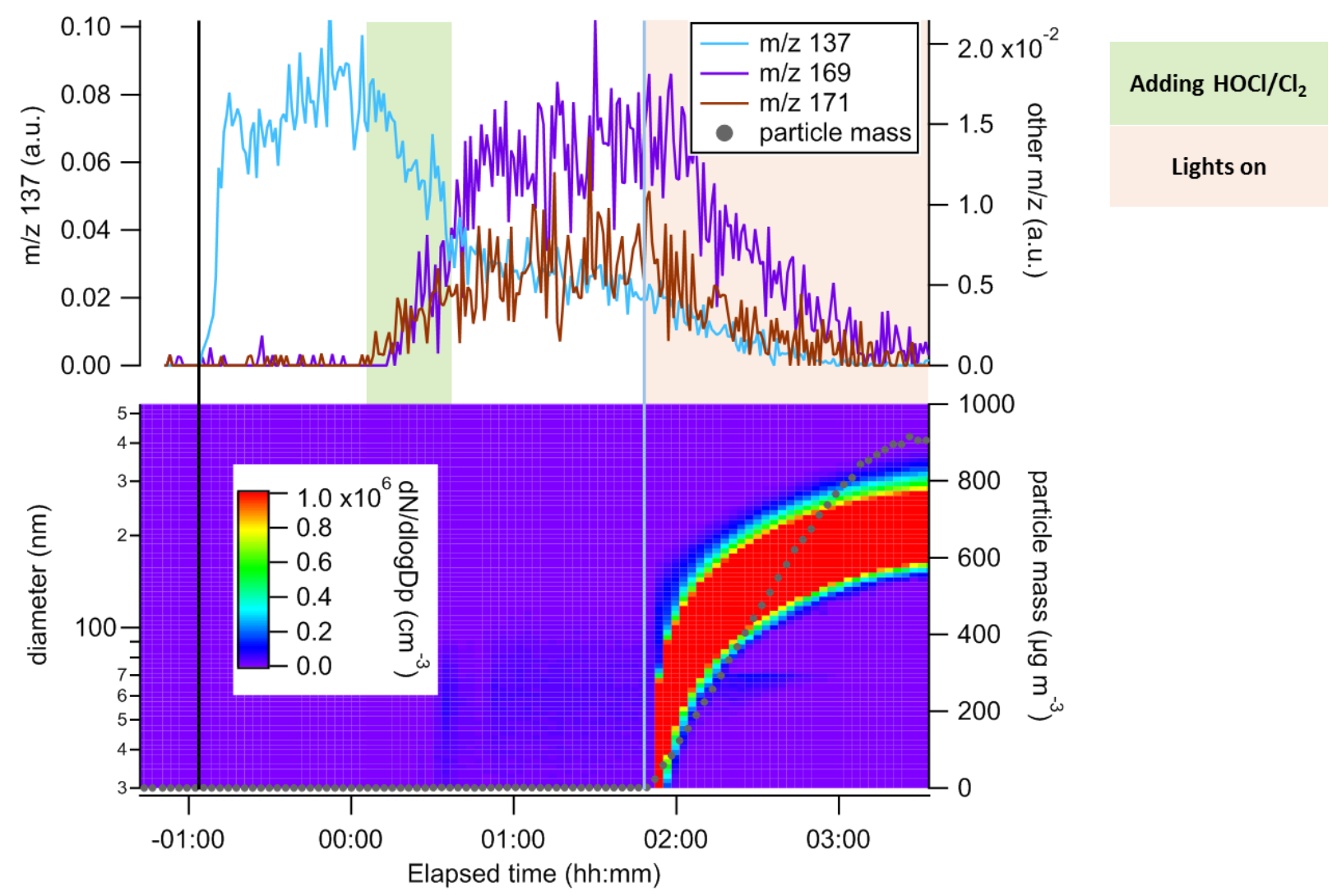

Figure S4. Time evolution of limonene and gas-phase products (PTR-MS traces, top panel), particle number size distribution (bottom panel, left axis) and particle mass (grey dots, bottom right axis) during limonene reaction with $\mathrm{HOCl}$ and $\mathrm{Cl}_{2}$ experiment. The initial mixing ratio of limonene is roughly $200 \mathrm{ppb}$ and the mixing ratios of $\mathrm{HOCl}$ and $\mathrm{Cl}_{2}$ are roughly 700 and $950 \mathrm{ppb}$ in the chamber. The black line indicates when limonene was added to the chamber. The shaded green periods show when $\mathrm{HOCl} / \mathrm{Cl}_{2}$ was added into the chamber, starting at time zero. The shaded pink area shows when indoor fluorescent lights were turned on, started at the blue line. $\mathrm{m} / \mathrm{z}$ 137 (light blue, top left axis) is protonated limonene and the other $\mathrm{m} / \mathrm{z}$ (top right axis) are different reaction products. 

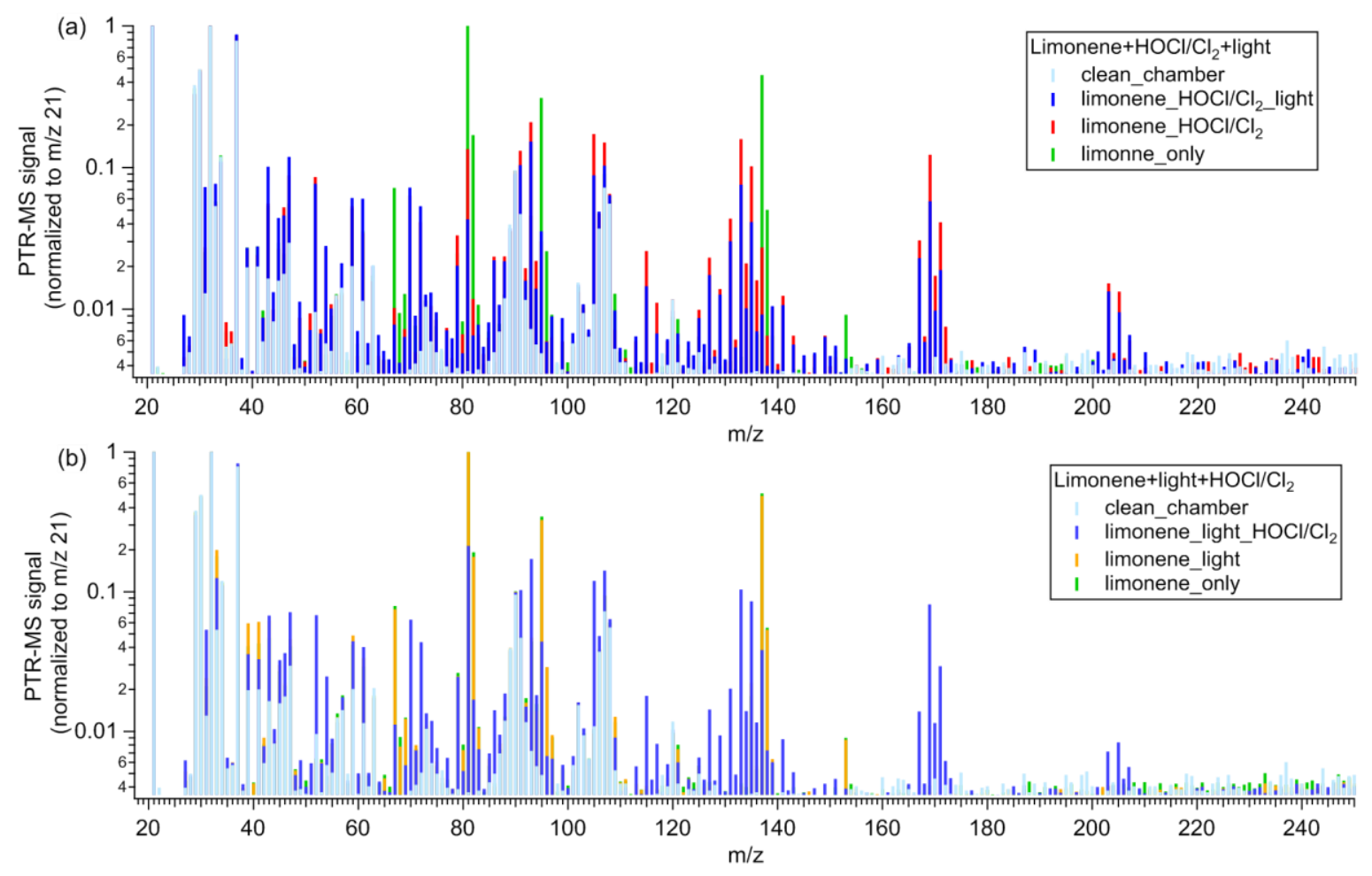

Figure S5. PTR-MS mass spectra (normalized to reagent ion $\mathrm{m} / \mathrm{z} 21$ ) for chamber air: (a) The same experiment as Figure 1a, i.e., turning on lights following adding $\mathrm{HOCl}$ and $\mathrm{Cl}_{2}$ (2 and $2.7 \mathrm{ppm}$ ) in a chamber filled with limonene $(1 \mathrm{ppm})$. The different colors show the averaged mass spectrum for different time periods and are overlaid, with the following order from the front to back: clean chamber in absence of limonene and $\mathrm{HOCl} / \mathrm{Cl}_{2}$ (light blue), limonene and $\mathrm{HOCl} / \mathrm{Cl}_{2}$ after turning on lights (blue), limonene and $\mathrm{HOCl} / \mathrm{Cl}_{2}$ before turning on lights (red), limonene only (green); (b) The same experiment as Figure S7, i.e. turning on lights after injecting limonene (1 ppm) in the chamber, followed by adding $\mathrm{HOCl}$ and $\mathrm{Cl}_{2}$ (2 and $2.7 \mathrm{ppm}$ ). The different colors show averaged mass spectrum for different time periods (from the front to back): clean chamber in absence of limonene and $\mathrm{HOCl} / \mathrm{Cl}_{2}$ (light blue), limonene and $\mathrm{HOCl} / \mathrm{Cl}_{2}$ with lights on (blue), limonene only with lights on (orange), limonene only (green). 


\section{Text S3. Particle formation under window light irradiation}

Figure S6. shows results from limonene $(1 \mathrm{ppm})$ and $\mathrm{HOCl} / \mathrm{Cl}_{2}(2$ and $2.7 \mathrm{ppm})$ reaction under window light. Limonene was added to the chamber at the black line. Its signal became stable after about $15 \mathrm{~min}$. Although in almost all experiments there were no particles present before turning on the lights, in this experiment a small number of particles was observed upon adding limonene into the 'clean' chamber, likely due to the presence of a small amount of unknown reactants in the chamber. This is despite the chamber being flushed overnight with clean air before the start of the experiment. At time zero, $\mathrm{HOCl} / \mathrm{Cl}_{2}$ was added into the chamber. Due to the presence of sodium phosphate buffer in the $\mathrm{NaOCl}$ solution, aerosol particles (approximately $100 \mathrm{~nm}$ in size) were generated from the bubbler and added to the chamber during $\mathrm{HOCl} / \mathrm{Cl}_{2}$ addition period. The initially-formed particles are relatively stable in number concentration after adding $\mathrm{HOCl} / \mathrm{Cl}_{2}$ in the chamber and before light exposure, with slow growth in particle size likely due to condensation of SVOCs formed during the $\mathrm{HOCl} / \mathrm{Cl}_{2}$ dark reaction. The low particle concentration and slow growth suggest the levels of the unknow reactant in the chamber are low and not enough to make significant aerosol mass, which is also supported by the relatively stable signal of limonene before $\mathrm{HOCl} / \mathrm{Cl}_{2}$ addition, i.e. no obvious decrease in $\mathrm{m} / \mathrm{z} 137$. After exposure to window sunlight, rapid particle nucleation and growth were observed, with over $1000 \mathrm{~g} \mathrm{~m}^{-3}$ particle mass formed after 1-hour reaction. The light intensity at different times of the experiment was measured and presented in Figure S2. The overlap of $\mathrm{HOCl} / \mathrm{Cl}_{2}$ absorbance with the windowlight at wavelengths $<500 \mathrm{~nm}$ confirms the potential for formation of $\mathrm{Cl}$ and $\mathrm{OH}$ radicals under window light irradiation, leading to chemistry that forms particles. Overall, the number and mass of particles formed in the chamber in the dark are insignificant compared to those after window light irradiation. In the same experiment, a membrane filter (PallFlex, Emfab ${ }^{\mathrm{TM}}$ filters, diam. $47 \mathrm{~mm}$ ) was installed in front of the PTR-MS inlet during different time periods to investigate the influence of the filter on PTR-MS signals. The blue highlighted periods in Figure S6 shows when the filter was removed from the PTR-MS inlet. There was a slight drop of PTR-MS signal when the filter was present because limonene may be trapped on the filter, but the influence is not substantial. Due to the large concentration of particles formed during the experiment, we decided to keep the filter on for the PTR-MS for all other experiments to prevent inlet clogging. 


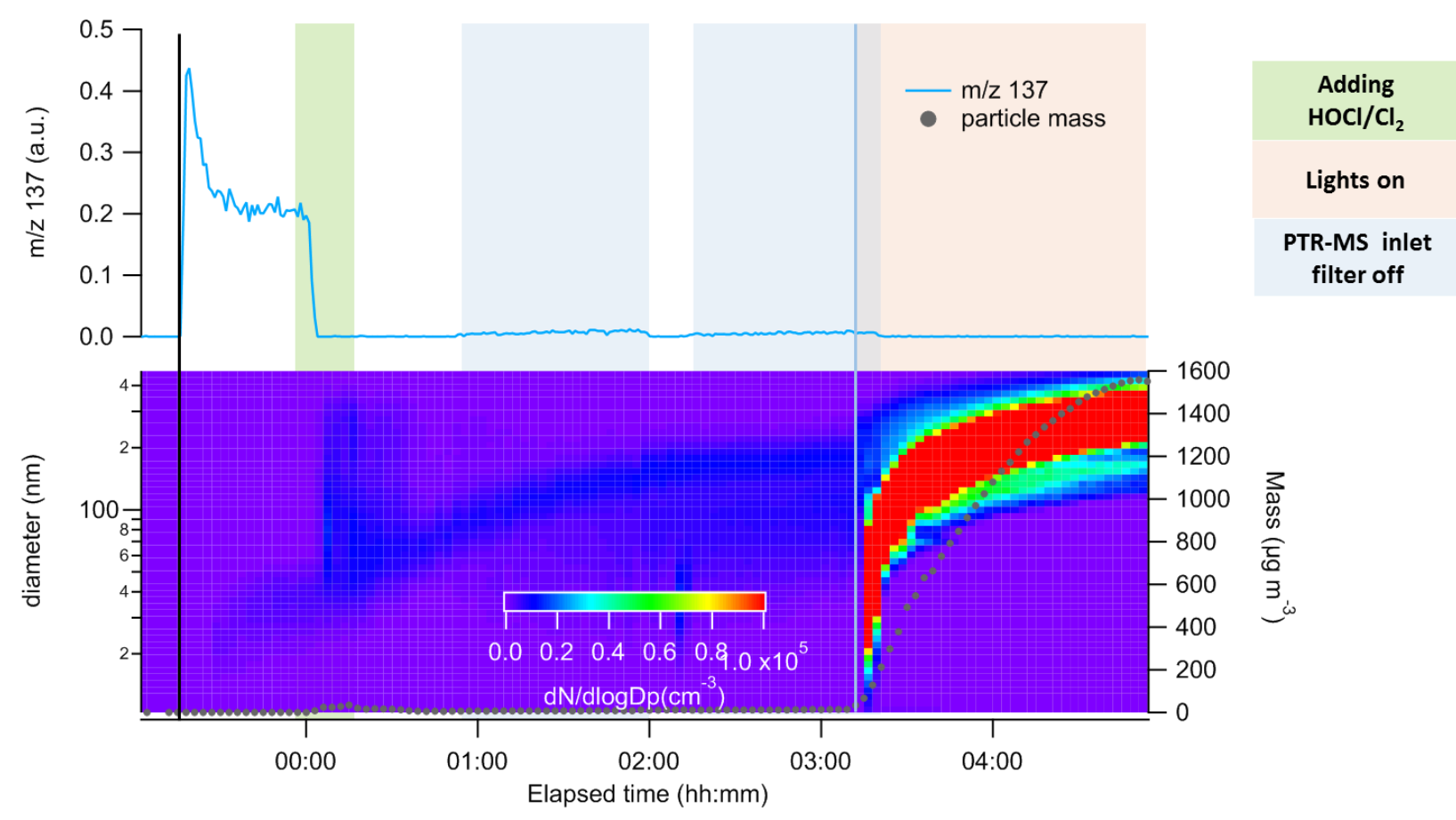

Figure S6. Time evolution of limonene ( $\mathrm{m} / \mathrm{z} 137$, top panel), particle number size distribution (lower panel, left axis) and particle mass (grey dots, lower panel right axis) during limonene reaction with $\mathrm{HOCl}$ and $\mathrm{Cl}_{2}$ experiment under window light. The initial mixing ratios of limonene, $\mathrm{HOCl}$ and $\mathrm{Cl}_{2}$ in the chamber are roughly 1,2 and $2.7 \mathrm{ppm}$. The black line indicates when limonene was added to the chamber. The shaded green period shows when $\mathrm{HOCl} / \mathrm{Cl}_{2}$ was added into the chamber, starting at time zero. The shaded blue periods show when a membrane filter in front of the PTR-MS inlet was removed. The shaded pink area shows when the chamber was exposed to window light, starting at the blue line. $\mathrm{m} / \mathrm{z} 137$ (light blue, top left axis) is protonated limonene. The initial fluctuation of the limonene signal after addition into the chamber is due to the mixing in the chamber. 


\section{Text S4. Turning on lights before adding $\mathrm{HOCl} / \mathrm{Cl}_{2}$}

In Figure S7, one experiment was conducted by turning on fluorescent lights before adding $\mathrm{HOCl} / \mathrm{Cl}_{2}$ into the chamber. We were able to test the influence of light on limonene behavior. The result suggests that there was no significant loss of limonene due to photolysis only. We observed a very rapid decay of limonene after $\mathrm{HOCl}$ and $\mathrm{Cl}_{2}$ was added into the chamber with lights on, at a rate (e-folding time, $\tau=40 \mathrm{~s}$ ) similar to that in experiments in the absence of light (Figure 1a), and with similar dominant PTR-MS ions. Particle formation was observed immediately following adding $\mathrm{HOCl} / \mathrm{Cl}_{2}$, consistent with observation from other experiments when particles formed with lights on, due to photolysis of $\mathrm{HOCl}$ and $\mathrm{Cl}_{2}$.

The dominant ions $\mathrm{m} / \mathrm{z} 169$ and 171 increased immediately after adding $\mathrm{HOCl} / \mathrm{Cl}_{2}$ and started to decrease after about $30 \mathrm{~min}$, suggesting there are both formation and loss of products with either PTR-MS parent or fragment ions at $\mathrm{m} / \mathrm{z} 169$ and 171 . The estimated photolysis lifetime of $\mathrm{HOCl}$ and $\mathrm{Cl}_{2}$ is 385 and 53 hours (Table S2), thus even with lights on, $\mathrm{HOCl}$ and $\mathrm{Cl}_{2}$ are present and can react with limonene, resulting in similar products as formed in the dark. It is also possible that reaction of limonene with $\mathrm{Cl}$ or $\mathrm{OH}$ radical also produces $\mathrm{m} / \mathrm{z} 169$ and 171 . Different from the scenario when lights were turned on after adding $\mathrm{HOCl} / \mathrm{Cl}_{2}$ in Figure $1 \mathrm{a}$, the increase of $\mathrm{m} / \mathrm{z} 169$ and 171 was faster $(\tau=813 \pm 162$ and $736 \pm 245 \mathrm{~s}$, respectively) in Figure S7 than those in Figure 1a ( $\tau=2157 \pm 440$ and $2590 \pm 815 \mathrm{~s}$, respectively). In other words, the increase of $\mathrm{m} / \mathrm{z} 169$ and 171 continued for a shorter period till they started to decrease in Figure S7. A few reasons can explain this observation. First, it is possible that the loss processes of $\mathrm{m} / \mathrm{z}$ 169 and 171 are faster in Figure S7, e.g. products that give signals of m/z 169 and 171 in the PTR-MS are likely semi-volatile and they can condense onto particles that formed simultaneously, while in Figure 1a particle formation started later when lights were turned on. Second, further reactions of the species giving $\mathrm{m} / \mathrm{z} 169$ and 171 when lights, $\mathrm{Cl}$ and $\mathrm{OH}$ are present lead to a faster loss. These two reasons are consistent with the observation that in Figure $1 \mathrm{a}$ both $\mathrm{m} / \mathrm{z} 169$ and 171 started to decrease when lights were turned on, i.e. when particles were forming and $\mathrm{OH}$ and $\mathrm{Cl}$ were available. The scenario in Figure $\mathrm{S} 7$ represents a more realistic indoor environment, when indoor irradiation is likely available either from window light or fluorescent lights during bleach cleaning activities. 


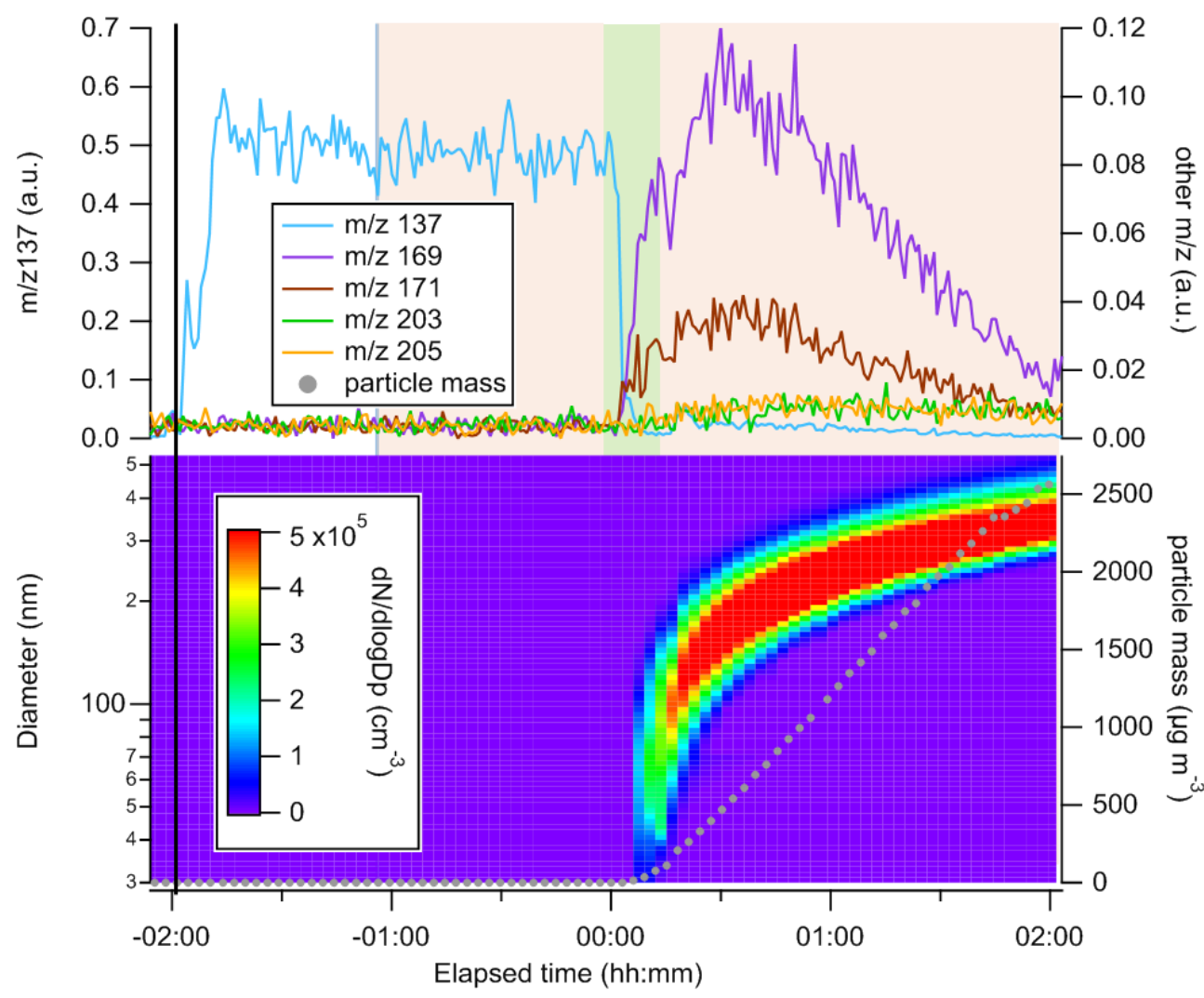

Adding $\mathrm{HOCl} / \mathrm{Cl}_{2}$

Lights on

Figure S7. Time evolution of limonene and gas phase products (PTR-MS traces, top panel), particle number size distribution (lower panel, left axis) and particle mass (grey dots, lower panel right axis) during limonene reaction with $\mathrm{HOCl}$ and $\mathrm{Cl}_{2}$ experiment under indoor fluorescent lights. The initial mixing ratios of limonene, $\mathrm{HOCl}$ and $\mathrm{Cl}_{2}$ in the chamber are roughly 1,2 and $2.7 \mathrm{ppm}$. The black line indicates when limonene was added to the chamber. The shaded green period show s when $\mathrm{HOCl} / \mathrm{Cl}_{2}$ was added into the chamber, starting at time zero. The shaded pink area shows when indoor fluorescent lights were turned on, starting at the blue line. 


\section{Text S5. $\alpha$-pinene and $\mathrm{HOCl} / \mathrm{Cl}_{2}$ experiment under fluorescent lights}

Figure 88 shows results from the $\alpha$-pinene oxidation experiment. There are similar observations compared to the limonene experiment. One difference is a slower decay rate of $\alpha$-pinene ( $\tau=\sim 1500 \mathrm{~s}$ ) from dark reaction with $\mathrm{HOCl}$ and $\mathrm{Cl}_{2}$ under similar conditions. This may relate to the lower reactivity of $\alpha$-pinene than limonene, since limonene contains two double bonds, including an exocyclic double bond, whereas $\alpha$-pinene only has one endocyclic double bond. Two dominant ions $\mathrm{m} / \mathrm{z} 169$ and 171 from limonene dark reaction were also observed for $\alpha$-pinene reaction. In addition, $\mathrm{m} / \mathrm{z} 173$ was also formed from $\alpha$-pinene oxidation, indicating that the reaction mechanism and products are possibly different from limonene reaction. There was some background of particles upon adding $\mathrm{HOCl}$ and $\mathrm{Cl}_{2}$ into the chamber, either from oxidation reactions or from the bubbler itself. However, significant higher number and mass concentration of particles formed after turning on indoor fluorescent lights. 


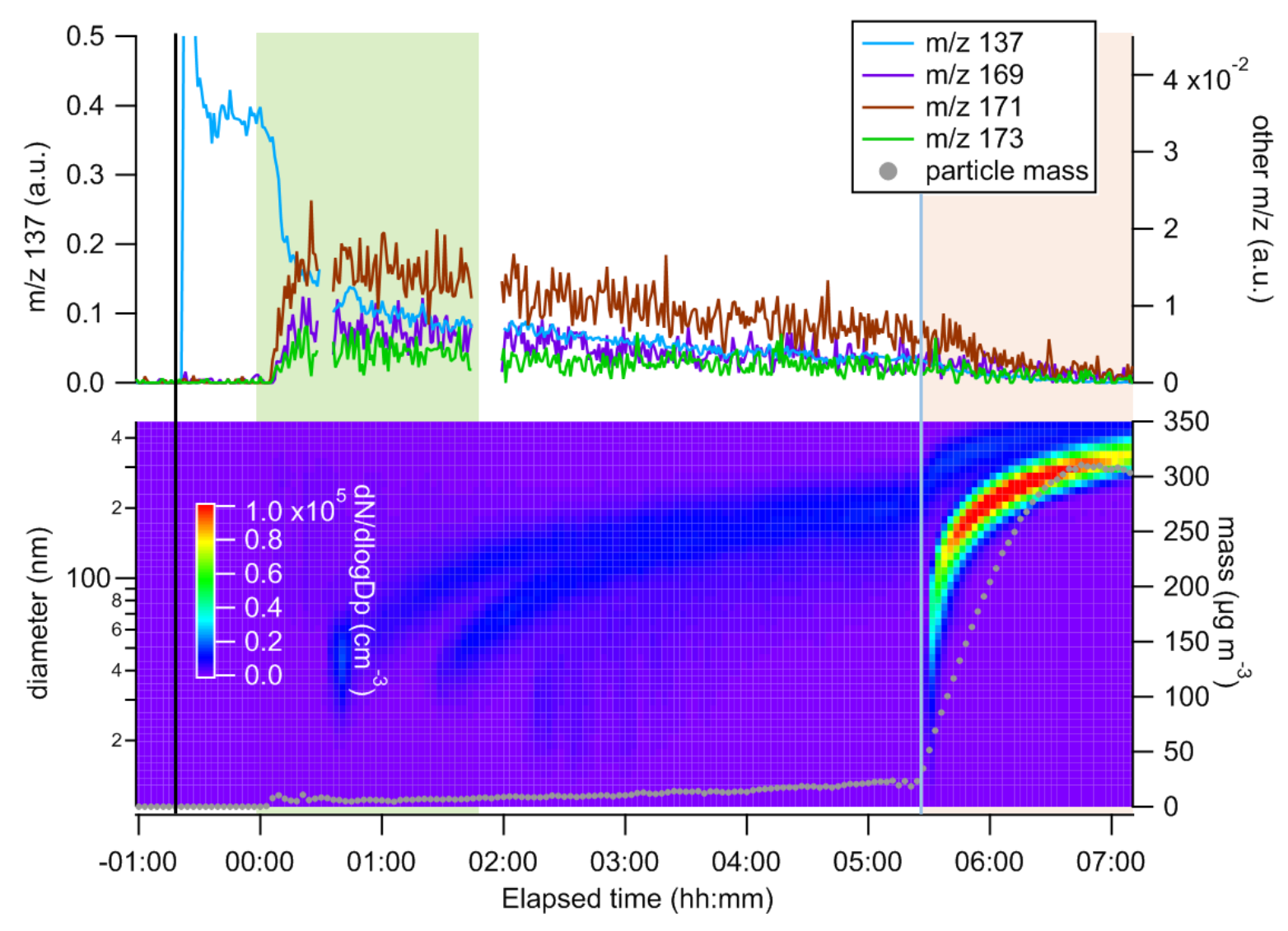

Figure S8. Time evolution of $\alpha$-pinene and gas phase products (PTR-MS traces, top panel), particle number size distribution (lower panel, left axis) and particle mass (grey dots, lower panel right axis) during limonene reaction with $\mathrm{HOCl}$ and $\mathrm{Cl}_{2}$ experiment under indoor fluorescent lights. The initial mixing ratios of $\alpha$-pinene, $\mathrm{HOCl}$ and $\mathrm{Cl}_{2}$ in the chamber are roughly 1,2 and $2.7 \mathrm{ppm}$. The black line indicates when $\alpha$-pinene was added to the chamber. The shaded green period shows when $\mathrm{HOCl} / \mathrm{Cl}_{2}$ was added into the chamber, starting at time zero. The shaded pink area shows when indoor fluorescent lights were turned on, starting at the blue line. 

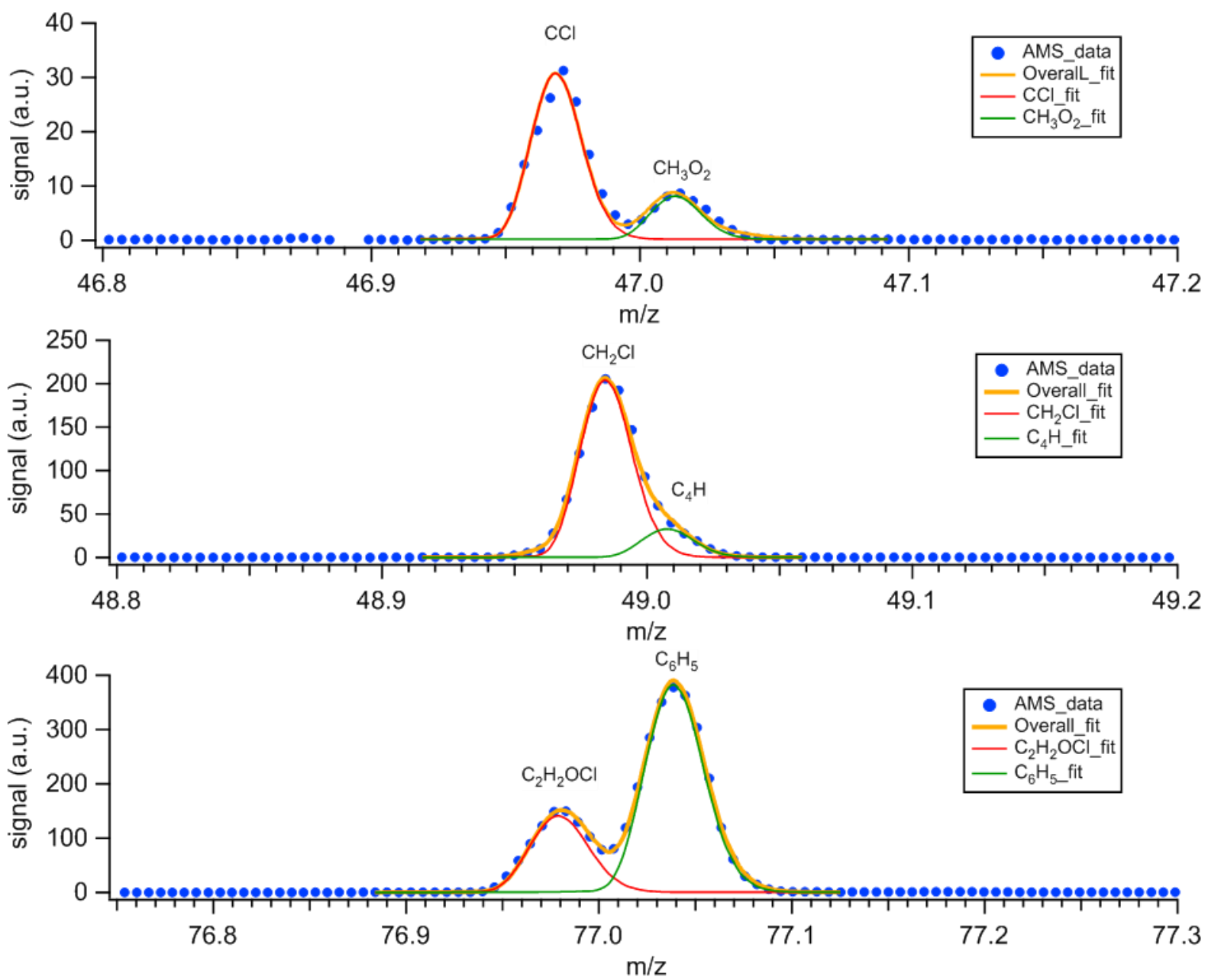

Figure S9. AMS peak fitting for chlorine containing fragment $\mathrm{CCl}^{+}, \mathrm{CH}_{2} \mathrm{Cl}^{+}$and $\mathrm{C}_{2} \mathrm{H}_{2} \mathrm{OCl}^{+}$. The overall fit is show $\mathrm{n}$ in orange lines. The dominant ions at the $\mathrm{m} / \mathrm{z}$ were shown in red and green lines. 


\section{References}

1. Burkholder, J. B.; Sander, S. P.; Abbatt, J.; Barker, J. R.; Huie, R. E.; Kolb, C. E.; Kurylo, M. J.; Orkin, V. L.; Wilmouth, D. M.; Wine, P. H., Chemical Kinetics and Photochemical Data for Use in Atmospheric Studies. Evaluation No. 18. Jet Propulsion Laboratory, Pasadena. JPL Publication 15-10. 2015. 